\title{
Percepção de Estudantes Sobre Saúde, Alimentação e Atividade Física Após Intervenção com a Metodologia da Problematização
}

\author{
Caroline Vargas Peres ${ }^{1}$ \\ Simone Lara ${ }^{2}$ \\ Jaqueline Copetti ${ }^{3}$ \\ Karoline Goulart Lanes ${ }^{4}$ \\ Max Castelhano Soares ${ }^{5}$
}

\begin{abstract}
Resumo
Neste texto optou-se por abordar temas em saúde por intermédio de metodologias ativas, utilizando a Metodologia da Problematização (MP), uma vez que essa ferramenta propicia ao aluno a valorização da realidade que o cerca, fazendo-0 refletir sobre ela. Foram selecionadas duas turmas do 7o ano do Ensino Fundamental. e em uma delas trabalhou-se os temas em saúde por meio de aula expositiva, e na outra os temas foram abordados pela MP. 0 instrumento de coleta de dados utilizado foi o Questionário de Percepção de Hábitos Saudáveis, aplicado antes e após a intervenção. Assim, foi possível constatar que houve mudança de percepção nos dois grupos de estudantes após a intervenção, porém na comparação intergrupos os estudantes do grupo da MP apresentaram maior conhecimento nos
\end{abstract}

1 Pós-graduada em Educação em Ciências, Universidade Federal do Pampa, campus Uruguaiana. carol_vargas@hotmail.com

2 Doutora em Educação em Ciências, mestre em Fisiologia Humana. Docente do curso de Fisioterapia da Universidade Federal do Pampa - Unipampa/RS. simonelara@ unipampa.edu.br

3 Doutora em Educação em Ciências: Química da Vida e Saúde (UFSM). Professora do curso de Fisioterapia da Universidade Federal do Pampa - Unipampa, Campus Uruguaiana. jaquecopetti@yahoo.com.br

4 Doutora em Educação em Ciências: Química da Vida e Saúde (UFSM). ktguria@yahoo.com.br

5 Mestre em Educação em Ciências: Química da Vida e Saúde (UFSM). maxcastelhano@ yahoo.com.br 
domínios avaliados quando comparados aos estudantes que participaram da aula expositiva. Com isso, evidencia-se que a MP foi mais eficiente para promover conhecimento sobre as temáticas em saúde do que as aulas expositivas.

Palavras-chave: Metodologia da problematização. Estudantes. Saúde.

\title{
PERCEPTION OF THE STUDENTS ON HEALTH, NUTRITION AND PHYSICAL ACTIVITY AFTER INTERVENTION BY PROBLEMATIZATION METHODOLOGY
}

\begin{abstract}
In this study we chose to address health issues through active methodologies, using the methodology of problematization (MP), since this tool provides the student with the appreciation of the reality that surrounds him, causing him to reflect on it. Two classes were selected from 7th year of elementary school, where in one of them worked up the health issues through lecture, and the other, the issues were addressed by the MP. The data collection instrument used was the Perception of Healthy Habits, applied before and after intervention. Thus, after the intervention, there was a change of perception in both groups of students, but the inter-group comparison, students of the MP group showed greater knowledge in the domains assessed, compared to students who had lecture. Thus, it is clear that the MP was more effective to promote knowledge on the issues of health, than lectures.
\end{abstract}

Keywords: Methodology of problematization. Students. Health.

Recebido em: 4/7/2017

Aceito em: 10/8/2017 
Ter conhecimento sobre saúde e seus temas relacionados no contexto da sala de aula, é de extrema importância para os alunos, pois este assunto é abordado em todos os lugares e, quanto mais se sabe sobre o tema, mais se promove qualidade de vida. É por intermédio dos conteúdos abordados nas aulas que se constrói um novo saber, e esses conteúdos devem ser trabalhados de maneira significativa para os alunos, oportunizando uma construção mútua de conhecimentos. Ensinar e promover saúde na escola é imprescindível, pois, segundo Costa, Silva e Diniz (2008), uma das formas de promover saúde e incentivar práticas de vida saudáveis e utilizar-se do processo de educação e saúde, quando se oportuniza o compartilhamento de saberes os mais variados possível na busca de soluções para diversas problemáticas.

Nesse sentido, Berbel (1998) descreve que as práticas relativas às metodologias ativas (como a Metodologia da Problematização - MP) vêm sendo utilizadas há quase duas décadas em alguns Estados no Brasil. Segundo a autora, a necessidade de comunicação de aprendizagem não é somente conclusiva e sim provocativa, com problemas para o desenvolvimento dos processos de ensinar e aprender, e as metodologias ativas desenvolvem essas habilidades. Segundo Borille et al. (2012), esse método tem como ponto de partida a realidade do sujeito e o cenário em que os vários problemas podem ser vistos, percebidos ou deduzidos, de maneira que possam ser estudados em conjunto ou entre os pares.

Sendo assim, esta pesquisa teve como objetivo identificar os efeitos da MP sobre a percepção de estudantes acerca dos temas saúde, alimentação e atividade física, bem como identificar se essa metodologia é mais eficiente para promover o conhecimento dos estudantes do que a metodologia de aulas expositivas. Logo, descrevemos a seguir pontos importantes sobre os processos de educação e saúde no ambiente escolar, bem como aspectos relativos às metodologias ativas no ensino-aprendizagem.

\section{Educação e saúde no contexto escolar}

O tema saúde nas escolas tornou-se obrigatório por meio do artigo $7^{\circ}$ da Lei 5.692 de 1971 (BRASIL, 1971), no qual as ações de saúde deveriam ser estabelecidas por meio dos programas de saúde nas escolas de primeiro e 
segundo graus, com o objetivo de estimular o conhecimento e a prática da saúde básica e da higiene. Com a Lei de Diretrizes e Bases da Educação No 9.394, os programas de saúde foram suprimidos, e a única alusão à saúde ocorria na referência ao dever do Estado com a educação escolar pública, o qual seria efetivado mediante a garantia de atendimento ao educando, no Ensino Fundamental público, por meio de programas suplementares de material didático-escolar, transporte, alimentação e assistência à saúde (BRASIL, 1996). A partir de então, a abordagem com o tema saúde é obrigatória nas escolas, dentro da sala de aula.

Sob esse olhar, os Parâmetros Curriculares Nacionais-PCNs (BRASIL, 1997) buscam um tratamento didático a fim de contemplar a complexidade do currículo para ganhar uma flexibilidade e abertura, priorizando e contextualizando os temas de acordo com as diferentes realidades locais e regionais. Uma das finalidades dos temas transversais, de acordo com os PCNs, é favorecer a compreensão da realidade e estimular a participação social, ou seja, os alunos podem desenvolver a capacidade de se posicionar diante das questões que interferem na vida coletiva, superar a indiferença e intervir de forma responsável. Os temas do currículo também devem possibilitar uma visão ampla e consistente da realidade local e sua inserção no mundo, além de desenvolver um trabalho educativo que possibilite uma participação social dos alunos.

De fato, a saúde integra um dos temas transversais, uma vez que está presente em nosso cotidiano de diferentes maneiras, sejam em notícias, informações, conhecimentos, questionamentos na escola, em casa e em vários meios de transmissão, mídia, pesquisa, Internet, livros. Dessa forma, devido ao fato de que essa temática é vivenciada no dia a dia dos indivíduos, ela deve prioritariamente ser abordada na escola, por meio dos conteúdos curriculares, em seu aspecto transversal, perpassando as diferentes áreas de conhecimento.

Nesse contexto, temáticas incluindo alimentação, atividade física e doenças crônicas são importantes para a aprendizagem dos estudantes, pois a falta de conhecimento pode aumentar o risco para o desenvolvimento das Doenças Crônicas Não Transmissíveis (DCNTs). Estas são as principais causas de óbitos no mundo e têm gerado elevado número de mortes prematuras, perda de qualidade de vida entre outros problemas, de acordo com a Organização Mundial da 
Saúde (2014). Segundo Malta, Morais Neto e Silva Junior (2011), esse impacto pode ser revertido por meio de um maior conhecimento, mediante intervenções amplas e custo-efetivas de promoção de saúde, para redução de seus fatores de risco e pela melhoria da atenção à saúde.

De forma complementar, a obesidade em crianças e adolescentes, entre outras doenças como diabete mellitus, podem ser evitadas por meio de uma alimentação balanceada e a prática de atividade física regularmente. Segundo Melo, Luft e Meyer (2004), a criança e o adolescente tendem a ficar obesos quando sedentários, e a própria obesidade poderá fazê-los ainda mais sedentários. Trata-se, sem dúvida, de uma questão educacional, de responsabilidade da família e da escola (SANTOS; CARVALHO; GARCIA JUNIOR, 2007). A escola, por sua vez, deve assumir um protagonismo em relação à saúde integral dos indivíduos em idades precoces, mediante um ensino em saúde eficaz, uma vez que o conhecimento leva à ação e transformação. Por isso, ressalta-se a importância de o tema saúde ser estudado e aprendido em conjunto com os respectivos conteúdos escolares.

Nesse sentido, Darido (2012) define conteúdo como uma seleção de formas ou saberes culturais, conceitos, explicações, raciocínios, habilidades, linguagens, valores, crenças, sentimentos, atitudes, interesses, modelos de conduta, etc., cuja assimilação é considerada essencial para que se produza um desenvolvimento e uma socialização adequada ao aluno. A autora complementa afirmando que os conteúdos são os meios pelos quais o aluno deve analisar e abordar a realidade de forma que, com isso, possa ser construída uma rede de significados em torno do que se aprende na escola e do que se vive.

Sob esse aspecto, Freire (1996) descreve que o melhor ponto de partida para ensinar está nas reflexões, ensinar os alunos a serem indagadores e curiosos, não somente aprender por aprender, mas para transformar a realidade, intervindo e recriando-a. Assim, a aprendizagem significativa é o mecanismo humano para adquirir e armazenar a vasta quantidade de ideias e informações, representadas em qualquer campo de conhecimento. A fim de que a aprendizagem seja significativa, existe a necessidade de estabelecer uma relação entre o conteúdo que vai ser aprendido e aquilo que o aluno já sabe, levando em consideração o 
que o ele traz consigo (RONCA, 1994). O autor reitera que esse conjunto de conhecimentos representa a estrutura cognitiva, e assim, consiste na variável mais importante que o professor deve levar em consideração no ato de ensinar.

Nessa perspectiva, segundo Moreira (2011), a essência do processo da aprendizagem significativa está em algum conceito ou proposição que já lhe é significativo e adequado para interagir com a nova informação. É desta interação que emergem, para o aprendiz, os significados dos materiais potencialmente significativos, bem como o conhecimento prévio se modifica pela aquisição de novos significados. Para que ela seja significativa, portanto, o professor deve proporcionar ao aluno a oportunidade de interagir com o objeto do conhecimento, pois é necessário valorizar as concepções prévias dos alunos, a fim de que se possa alcançar a melhor forma de apropriação do conhecimento científico, respeitando o conteúdo de bagagem que o estudante traz consigo. Os conteúdos que são trabalhados em sala de aula devem ser construídos de forma significativa para os alunos, associando as suas vivências e tendo como base a construção de um novo e mais sólido conhecimento.

Dentro das novas tendências pedagógicas, surgem as metodologias ativas de ensino-aprendizagem, que estão centradas nos princípios da pedagogia interativa, crítica e reflexiva (FERNANDES et al., 2003). Tais ferramentas envolvem a participação ativa dos estudantes no processo dinâmico de construção do conhecimento, resolução e avaliação de problemas, trazendo o educando para o papel de sujeito ativo de seu crescimento, protagonista do processo.

\section{Metodologias Ativas no Processo de Ensino Aprendizagem}

Metodologias ativas vêm sendo utilizadas na área de saúde e educação e também no Ensino Superior. Segundo Berbel (2012), essa ferramenta proporciona vários benefícios, entre eles o fato de os alunos serem pesquisadores, ou seja, selecionam o problema para estudo, bem como consideram a realidade 
para intervir em busca de respostas para os problemas. Na MP, a relação entre teoria e prática é constante, e o pensamento crítico do aluno é estimulado em cada etapa do processo.

A MP traz como ponto de partida a observação da realidade, de maneira ampla, o aprofundamento teórico com discussão e análise do problema, criando hipóteses de solução utilizando sua criatividade para realizar possíveis mudanças no contexto que está sendo observado e uma aplicação à realidade com a finalidade de transformação. Assim, o aluno também é protagonista do conhecimento e os conteúdos passam a ser mais bem assimilados, uma vez que suas vivências e experiências são consideradas e valorizadas. Para Cyrino (2004), a educação problematizadora trabalha a construção de conhecimentos a partir da vivência de experiências significativas. Desta forma, esta metodologia busca identificar os conhecimentos prévios dos alunos para, a partir desses conhecimentos, proporcionar momentos de interação do que já se sabe com a procura significativa de um conhecimento o mais perto possível do científico.

A problematização aparece nos anos 60 como uma teoria do conhecimento baseada na filosofia da educação construtivista, na qual a problematização revela a força motivadora da aprendizagem (BERBEL, 2012). O autor destaca que, por meio desta metodologia, o participante está em condições de fazer uma síntese dessa nova compreensão e dessa nova consciência, quando chega a conclusões na teorização e quando elabora hipóteses de solução para o problema.

Assim, a motivação do educando constitui-se a partir da identificação de uma situação-problema da realidade e este problema se configura em uma aproximação crítica do estudante, conduzindo-o a um processo de compreensão, reflexão e crítica sobre a realidade na qual está inserido. A MP defende a concepção de um educando ativo no seu processo de aprendizagem, partindo de problemas vivenciados por ele em suas relações com o mundo, e que a educação problematizadora apoia-se na relação dialógica entre professores e estudantes, resultando num processo emancipatório, conforme reiteram Marinho, Silva e Ferreira (2012). De fato, por meio desse processo, associado à reflexão sobre as 
possíveis causas e determinantes do problema, Berbel (2012) reitera que uma característica da MP é a mobilização social dos alunos como cidadãos ativos na construção da história de seu tempo, mesmo que em pequena dimensão.

\section{Metodologia}

Trata-se de uma intervenção educativa, de caráter quantitativo e descritivo, no qual foram incluídos 24 estudantes, do $7^{\circ}$ ano do Ensino Fundamental, regularmente matriculados em uma escola pública municipal de Alegrete/RS. Tanto a escola quanto as turmas de estudantes foram selecionadas por sorteio.

A fim de identificar o nível de conhecimento dos estudantes sobre os temas relacionados à saúde, optou-se pelo uso do Questionário de Percepção de Hábitos Saudáveis (QPHAS), composto por 30 questões fechadas (GUEDES; GRONDIN, 2002). Este instrumento tem por objetivo verificar a percepção de adolescentes em relação aos conceitos propostos na literatura nos seguintes aspectos: a) do controle de peso corporal; b) da alimentação saudável; c) da prática de atividades físicas relacionada à saúde (Quadro 1).

\section{Quadro 1 - Questionário de Percepção de Hábitos Saudáveis (QPHAS)}

Domínio - controle de peso corporal

Na maioria das vezes o excesso de gordura corporal ocorre devido à elevada ingestão de alimentos e da falta de atividade física.

A maneira com que a gordura está distribuída no corpo - maiores quantidades no abdômen ou quadril - não influencia a saúde das pessoas.

Doenças como diabetes, pressão alta, derrame, doenças do coração, são mais comuns em pessoas gordas que em pessoas não gordas.

Crianças e adolescentes gordos têm maiores chances de se tornarem também adultos gordos.

O excesso de gordura e de peso corporal é apenas um problema estético.

A quantidade de alimento que ingerimos, independentemente da atividade física que fazemos, determinará a quantidade de peso corporal que temos.

Crianças e adolescentes que fazem uso de cigarro e bebidas alcoólicas têm maiores chances de ficarem doentes na idade adulta.

A genética (características físicas que herdamos de nossos pais) tem maior influência no aumento da quantidade de gordura corporal que os aspectos do meio ambiente (alimentação e atividade física). A atividade física regular, juntamente com a alimentação, adequada pode beneficiar a saúde de pessoas gordas e não gordas. 
Produtos e métodos como chás, cremes, massagens, etc., podem substituir de maneira saudável a atividade física e a alimentação para controlar o peso corporal.

Domínio - alimentação saudável

Para a nossa saúde o que importa é apenas a quantidade de alimentos que comemos e não o tipo de alimentos que ingerimos (frutas, cereais, hortaliças, leite, carne, etc.).

Por causa da sua importância para o funcionamento de nosso organismo devemos evitar a perda excessiva de água (suar demasiadamente, fazer sessões de sauna muito prolongadas, tomar medicamentos diuréticos, exercitar-se com grande quantidade de roupa, etc.).

Os alimentos de origem vegetal são os que têm menos gordura e que fornecem os principais nutrientes para o nosso corpo.

Quando uma pessoa que fez dietas para emagrecer rapidamente retorna à alimentação "normal", ela permanece com o mesmo peso corporal pós-dieta.

As vitaminas e os sais minerais não fornecem energia para o nosso corpo, mas ajudam em seu funcionamento.

Apenas os alimentos de origem animal fornecem energia ao nosso corpo.

As gorduras de alimentos de origem vegetal prejudicam a nossa saúde tanto quanto as gorduras de alimentos de origem animal.

Os alimentos industrializados (lanches como x-salada, cachorro-quente, refrigerantes, chocolates, sorvetes, etc.) são tão saudáveis quanto os alimentos naturais (frutas, verduras, leite, cereais).

Grandes quantidades de alimentos ricos em proteína (carne, leite, ovos, etc.) podem aumentar os depósitos de gordura no nosso corpo.

Os alimentos ricos em carboidratos (massas, pães e cereais) são aqueles que deverão oferecer maior quantidade de energia para o nosso corpo.

Domínio - prática de atividades físicas relacionada à saúde

Por não serem considerados exercícios físicos, os esforços físicos realizados nas tarefas domésticas, brincadeiras ativas e ocupações profissionais não ajudam a preservar e a melhorar a saúde. Dependendo das condições físicas de cada pessoa, os melhores exercícios físicos para a saúde são aqueles realizados com intensidade de baixa a moderada (caminhar, correr, nadar, pedalar, etc.). A prática de esportes (voleibol, basquetebol, futebol, handebol, etc.) é a única forma de fazer atividade física para a saúde.

Os efeitos benéficos do exercício físico para a saúde permanecem em nosso organismo mesmo depois de nos tornarmos sedentários novamente.

A execução de exercícios de flexibilidade pode reduzir a incidência de lesões músculo-osteoarticulares.

Quando fazemos exercícios físicos, a gordura corporal pode ser transformada em músculo.

Devemos fazer exercício físico entre 3 e 5 vezes na semana, preferencialmente em dias não consecutivos.

O ideal é que cada sessão de exercício físico voltado à promoção da saúde tenha uma duração mínima de 30 minutos.

Os exercícios físicos realizados com pesos (musculação) e o uso de substâncias anabólicas (anabolizantes) são essenciais para a nossa saúde, pois aumentam de forma excessiva os nossos músculos. Os exercícios físicos com pesos (musculação), mesmo que não ofereçam ganho significativo de massa muscular, são importantes para a nossa saúde.

Fonte: GUEDES; GRONDIN, 2002. 
As questões foram lidas, uma a uma, pela pesquisadora, para ficar claramente esclarecido pelos alunos, reduzindo assim as chances de possíveis dúvidas. Os participantes posicionaram-se diante das questões conforme sua percepção/opinião, considerando que cada questão apresenta alternativas de respostas equivalentes à pontuação entre 0 e 4 , sendo possível, portanto, alcançar pontuação máxima de 120 pontos (30 questões x 4 pontos). $\mathrm{O}$ valor 4 corresponde à maior percepção e o valor 1 à menor percepção. Valor 0 (zero) foi atribuído às questões sobre as quais os sujeitos não tenham opinião formada com relação ao conhecimento apresentado.

Após a aplicação do questionário aos estudantes selecionados, foi definida, por sorteio, uma turma que iria compor o Grupo Controle (GC), uma vez que receberiam aulas expositivas sobre os temas em saúde, e a outra turma que formaria o Grupo Intervenção (GI), cujos alunos desenvolveriam atividades por meio da MP visando à abordagem dos temas relacionados à saúde.

Assim, os alunos do GC receberam aulas expositivas por meio de palestras, elaboradas pelo pesquisador e apresentadas de forma expositiva simples, por explanação com slides. O conteúdo versou sobre os temas relativos ao questionário (controle de peso corporal, alimentação saudável e prática de atividades físicas relacionadas à saúde). Os slides continham textos e figuras, com curiosidades sobre os respectivos temas. Ao final, foi aberto espaço para os questionamentos dos alunos. O questionário pós-intervenção foi aplicado 15 dias após o término das atividades de intervenção.

Já com os alunos do GI os temas em saúde foram abordados sob a ótica da MP, tendo como mediadora a pesquisadora responsável, e as atividades basearam-se na proposta da MP com base no arco de Maguerez (Figura 1) como um norteador da pesquisa. 
Figura 1 - Modelo do Arco de Maguerez

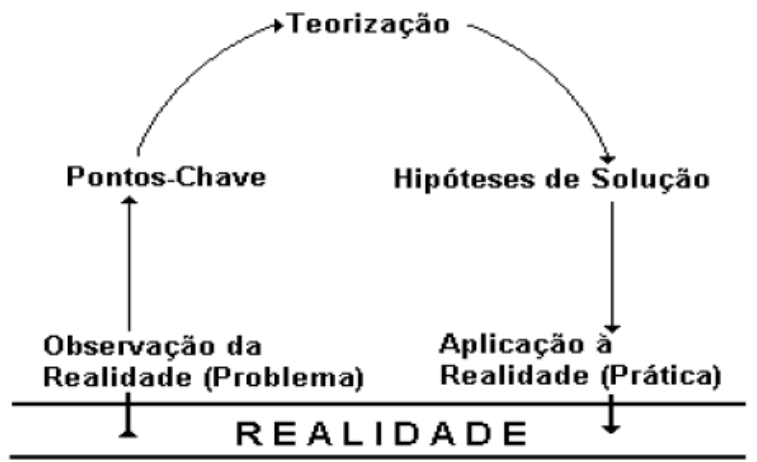

Fonte: BORDENAVE; PEREIRA, 1989.

Na metodologia da problematização são propostas cinco etapas que se desenvolvem a partir da realidade ou um recorte da realidade (BERBEL, 2012). A primeira é a observação da realidade social, concreta, pelos alunos, a partir de um tema ou unidade de estudo. Para realizar essa fase na pesquisa os alunos foram orientados pelo professor a olhar atentamente e registrar sintetizadamente o que perceberem sobre a parcela da realidade em que o tema estava sendo vivido. Com essa observação permitiu-se aos alunos a identificação de dificuldades, que foram transformadas em problemas. As discussões entre o grupo sobre a observação passaram a ser a referência para a próxima etapa (pontos-chave). Nessa fase os alunos foram levados a refletir primeiramente sobre as possíveis causas do problema em estudo. Por que será que esse problema existe? Foram listados alguns tópicos a serem estudados e perguntas a responder; formando assim os pontos-chave que serão desenvolvidos na próxima etapa. A terceira etapa é a da teorização, a qual consiste na investigação propriamente dita. Os alunos organizaram-se tecnicamente e buscaram as informações científicas que necessitavam sobre o problema, dentro de cada ponto-chave. A quarta etapa é a das hipóteses de solução. Nesta fase os alunos elaboraram as possíveis soluções; foram levantadas perguntas sobre as possíveis soluções; o que precisa acontecer para que o problema seja solucionado? Então foram criadas hipóteses de solução e sugestões criativas para realizar mudanças no contexto no qual estão inseridos. 
Foi sugerido que os alunos propusessem uma aplicação à realidade e soluções viáveis com a finalidade de transformação, pois acredita-se que transformações, ainda que em pequeno grupo, já representem uma conscientização que poderá repercutir em vários grupos maiores como os amigos, a família, etc. A quinta e última etapa é a da aplicação à realidade, quando os grupos apresentaram seus respectivos temas em mini- oficinas, por meio de cartazes, para o restante da turma, atividade na qual todos participaram ativamente.

Considerando que a MP é fundamentada no humanismo, uma vez que reflete a participação ativa dos sujeitos, bem como seu contexto de vida, história e experiências prévias, os alunos foram divididos em três grupos e pesquisaram sobre os temas "controle de peso e obesidade, alimentação saudável e práticas de atividade física”. Após a divisão dos grupos, foram levantados questionamentos e dúvidas que eles tinham sobre os temas. A partir de então foram propostas atividades com base na MP, em que os alunos deveriam buscar o conhecimento sobre o tema do seu grupo. Para tanto, foram utilizados livros, revistas, jornais, vídeos e construção de material no grupo, como os cartazes. Os instrumentos de pesquisa foram disponibilizados pela pesquisadora e pela escola, e cada grupo escolheu o(s) seu(s). A aplicação dos questionários pós-intervenção, assim como no grupo anterior, foi realizada 15 dias após o término das atividades de intervenção.

Para a análise dos dados foi utilizado o programa SPSS, versão 20.0, no qual foi utilizada análise descritiva, por meio de medidas de média e desvio padrão. Após testagem de normalidade dos dados, indicou-se uma distribuição paramétrica. Desta forma, as diferenças entre as testagens (pré e pós-testes) foram avaliadas pelo teste $t$ de student pareado. Para comparação entre os dois grupos (GI e GC) foi utilizado o teste t de student para amostras independentes. Para todas as análises foi considerado um nível de significância de 0,05. 


\section{Resultados e discussão}

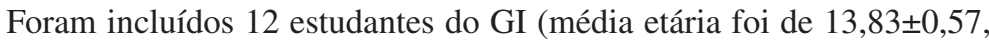
sendo 5 meninos e 7 meninas), e 12 estudantes do GC (média de idade de

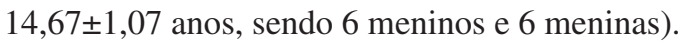

A Tabela 1 revela a percepção dos estudantes quanto aos três domínios avaliados por meio do QHAS, antes e após a intervenção. Foi possível evidenciar que houve aumento do nível de conhecimento em todos os domínios avaliados, pós-intervenção, em ambos os grupos $(\mathrm{p}<0,01)$. Desta forma, podemos inferir que tanto a MP quanto a metodologia por aula expositiva foi eficaz para promover um maior conhecimento nos estudantes.

Tabela 1 - Percepção dos estudantes sobre os domínios do QHAS pré e pós-intervenção

\begin{tabular}{|l|l|l|l|l|l|l|}
\hline Variável & \multicolumn{2}{|l|}{ Grupo Intervenção } & & \multicolumn{2}{l|}{ Grupo Controle } & \\
\hline & Pré & Pós & P & Pré & Pós & P \\
\hline Peso corporal & $27,17 \pm 3,76$ & $39,58 \pm 0,51$ & $<0,01^{*}$ & $26,50 \pm 2,97$ & $32,50 \pm 2,68$ & $<0,01^{*}$ \\
\hline $\begin{array}{l}\text { Alimentação } \\
\text { saudável }\end{array}$ & $26,25 \pm 3,36$ & $38,50 \pm 1,83$ & $<0,01^{*}$ & $27,25 \pm 4,90$ & $32,67 \pm 3,11$ & $<0,01^{*}$ \\
\hline $\begin{array}{l}\text { Prática de ativi- } \\
\text { dade física }\end{array}$ & $21,83 \pm 5,16$ & $38 \pm 2,04$ & $<0,01^{*}$ & $21,67 \pm 7,67$ & $31,75 \pm 2,76$ & $<0,01^{*}$ \\
\hline
\end{tabular}

Fonte: Os autores, 2017.

Teste t pareado, ${ }^{*} \mathrm{p}<0,05$ indicam diferença estatisticamente significativa.

A comparação do nível de conhecimento sobre os temas do QHAS entre os grupos está presente na Tabela 2. Foi possível verificar que antes do estudo os grupos apresentavam o mesmo nível de conhecimento sobre os domínios avaliados pelo questionário. Após a intervenção, porém, houve diferença entre os grupos nos três domínios considerados, indicando um melhor nível de conhecimento nos estudantes do GI $(\mathrm{p}<0,01)$.

Sendo assim, podemos afirmar que, mesmo havendo mudança de percepção nos dois grupos após a intervenção, os estudantes do GI apresentaram maior conhecimento nos três domínios avaliados, quando comparados aos estudantes do GC, evidenciando que a MP foi mais eficaz para promover uma melhor percepção sobre as temáticas analisadas do que as aulas expositivas tradicionais. 
Tabela 2 - Comparação da percepção dos estudantes sobre os domínios do QHAS entre os grupos

\begin{tabular}{|l|l|l|l|l|l|l|}
\hline Variável & $\begin{array}{l}\text { Grupo Inter- } \\
\text { venção }\end{array}$ & Grupo Controle & & $\begin{array}{l}\text { Grupo Inter- } \\
\text { venção }\end{array}$ & $\begin{array}{l}\text { Grupo Con- } \\
\text { trole }\end{array}$ & \\
\hline & Pré & Pré & P & Pós & Pós & P \\
\hline $\begin{array}{l}\text { Peso cor- } \\
\text { poral }\end{array}$ & $27,17 \pm 3,76$ & $26,50 \pm 2,97$ & 0,63 & $39,58 \pm 0,51$ & $32,50 \pm 2,68$ & $<0,01$ \\
\hline $\begin{array}{l}\text { Alimentação } \\
\text { saudável }\end{array}$ & $26,25 \pm 3,36$ & $27,25 \pm 4,90$ & 0,56 & $38,50 \pm 1,83$ & $32,67 \pm 3,11$ & $<0,01$ \\
\hline $\begin{array}{l}\text { Prática de } \\
\text { atividade } \\
\text { física }\end{array}$ & $21,83 \pm 5,16$ & $21,67 \pm 7,67$ & 0,95 & $38 \pm 2,04$ & $31,75 \pm 2,76$ & $<0,01$ \\
\hline
\end{tabular}

Fonte: Os autores, 2017.

Teste $t$ para amostras independentes $* \mathrm{p}<0,05$ indicam diferença estatisticamente significativa.

Em estudo realizado por Deus et al. (2014), avaliou-se a aceitação, o comportamento e a aprendizagem dos alunos em relação a aulas centradas no professor e aulas centradas nos alunos. Com as últimas notou-se a participação mais efetiva dos alunos, tendo a oportunidade de participar e interagir com o professor. Essas constatações também foram percebidas em nosso estudo, em que no grupo que trabalhou com a MP foi notória a maior participação e interação da turma, com os próprios alunos buscando informação com o auxílio do professor, em seu papel de mediador.

A MP está sendo muito usada em pesquisas da área da saúde e educação, em que precisam ser criadas hipóteses e reflexões para uma possível ação. Nesse sentido, a MP foi utilizada em uma amostra de enfermeiros (MELO, 2013), a fim de formar profissionais mais bem preparados para o trabalho em equipe e para a integralidade da atenção à saúde, capazes de continuar a aprender durante a vida profissional. Esse estudo objetivou identificar as dimensões de problemas vivenciados pelos residentes de Enfermagem de um Programa de Residência Multiprofissional em Oncologia, e discutir possíveis avanços na construção do conhecimento sobre os problemas vivenciados por eles, com base na aplicação da MP. Os resultados evidenciaram que, com a MP, os participantes tiveram uma maior facilidade de chegar a construir uma solução, uma vez que eles 
levantaram possíveis hipóteses. Assim, esses autores reiteram que a área da saúde está utilizando a MP com o intuito de ter um olhar mais reflexivo, uma vez que são necessárias estratégias para a melhoria da ação, de acordo com a realidade que se está vivenciando.

Em outro estudo proposto por França (2013), objetivou-se analisar a práxis docente no desenvolvimento da metodologia com o Arco de Maguerez, no contexto da formação do enfermeiro, no curso de Graduação em Enfermagem de uma escola pública do Distrito Federal. A amostra da pesquisa foi concedida por dez docentes do curso, que desenvolveram práticas com os discentes em vários cenários de ensino-aprendizagem. Foi observado que a parte que menos se aplica é a da criação de hipóteses para solução, o que pode ser explicado por uma dificuldade de solucionar problemas. Os autores explicam que, quando se inicia essa habilidade, ainda na Educação Básica, tem-se mais tempo para desenvolvê-la, destacando-se a importância de se utilizar esse método desde o Ensino Básico nas escolas.

Pedrosa et al. (2011) analisaram as experiências, por meio do uso de metodologias ativas de problematização, sobre a formação técnica de agente da saúde, e identificaram que, por meio dessa ferramenta, o discente pode refletir sobre o seu processo de trabalho, sua realidade, sua profissão e sua relação com a comunidade. Desta forma, foi evidenciado que a metodologia problematizadora despertou nesses profissionais o senso crítico para a busca de mudanças em um contexto mais amplo.

Em pesquisa realizada por Copetti et al. (2015), foi possível evidenciar que as intervenções educativas atingiram seu propósito sobre os temas em saúde após o emprego da MP. Os autores evidenciaram que, por meio de metodologias ativas, o aluno constrói o conhecimento de forma participante, o que aumenta o interesse pelos temas abordados, tornando assim o processo de ensino-aprendizagem mais significativo. Esses achados corroboram com os dados do presente estudo, no qual os alunos que participaram da MP aumentaram significativamente seu conhecimento sobre os temas abordados. 
Ainda em um estudo realizado por Marin et al. (2010) foram analisadas as fortalezas e fragilidades dos métodos ativos de aprendizagem na ótica dos estudantes, e foi encontrado que a aprendizagem baseada em problemas representa uma modalidade que supera o modelo tradicional de ensino, em favor de uma forma de ensino-aprendizagem que considera a complexidade com o que a realidade se apresenta. Corroborando, o estudo de Gomes et al. (2010), realizado com estudantes dos cursos de Graduação e Pós-Graduação, buscou identificar a eficácia de metodologias ativas, no alcance dos objetivos propostos no programa das disciplinas. Os autores encontraram que é relevante sugerir a substituição do ensino, do processo de transmissão de conteúdos teóricos, para um ensino que promova um processo de construção do conhecimento, por meio de métodos ativos e de análise das situações da prática social.

Sob esse olhar, Maia et al. (2012) também encontraram resultados positivos em relação ao uso de ferramentas ativas no processo de ensino-aprendizagem, uma vez que, em seu estudo, o emprego de metodologias ativas favoreceu o desenvolvimento de competências dos discentes envolvidos na educação e promoção da saúde infantil, possibilitando-lhes uma abordagem eficaz e coerente sobre as temáticas. Indo ao encontro dessas considerações Mendes (2015), ao analisar minuciosamente as metodologias utilizadas no processo de ensino-aprendizagem, concluiu que o uso das metodologias ativas torna-se cada vez mais necessária, uma vez que oportuniza ao aluno a participação e promove a interação do grupo, tornando os conteúdos mais próximos dos alunos.

Por intermédio dos estudos descritos, foi possível identificar que a MP é utilizada com o intuito de educar um cidadão com mais autonomia e habilidade de resolver problemas, refletir, buscar, problematizar e criar estratégias para uma ação de acordo com a realidade na qual está inserido. Assim, no presente estudo, acredita-se que essa ferramenta foi mais eficaz para melhorar o conhecimento em saúde pelos alunos do que a metodologia tradicional, devido às suas próprias características de desenvolvimento, no que respeita ao protagonismo dos alunos na construção de seu conhecimento. Ademais, podemos ressaltar que por meio desta metodologia foi percebido um maior envolvimento dos alunos, uma vez que eles relatavam dúvidas e curiosidades sobre o tema e, a partir de então, 
ocorria uma reflexão. Enquanto no GC a informação foi recebida de forma professor-aluno, no GI essa informação foi fornecida por suas próprias dúvidas e curiosidades a partir do tema de estudo, o que possivelmente torna o assunto mais agradável e de real significância.

\section{Considerações Finais}

No presente estudo evidenciamos que a MP propiciou ao estudante a valorização da realidade, fazendo-o refletir sobre ela, questionando as razões, criando estratégias e tendo como ponto de partida a realidade do contexto no qual está inserido.

Adicionalmente, percebemos que os estudantes do grupo da MP apresentaram uma participação mais efetiva quando comparada ao outro grupo, e, possivelmente por esse fator, obtivemos melhores resultados em relação aos conhecimentos apresentados por eles. Reiteramos também que a MP propiciou aos estudantes a participação, a autonomia e a liderança como um grupo, no qual os aprendizes perceberam sua importância no desenvolvimento da contextualização teórica e na definição de hipóteses de solução para possíveis problemas.

Por fim, acreditamos que a MP é uma ferramenta de grande valia, não apenas para proporcionar conhecimentos sobre temas específicos, mas também para contribuir para a formação de um sujeito crítico, reflexivo, capaz de transformar sua realidade.

\section{Referências}

BERBEL, N. A metodologia da problematização com o Arco de Maguerez. Londrina: Eduel, 2012.

. A problematização e a aprendizagem baseada em problemas: diferentes termos ou diferentes caminhos? Interface - Comunicação, Saúde, Educação, v. 2, n. 2, p. 139154, 1998.

BORDENAVE, J.; PEREIRA, A. Estratégias de ensino aprendizagem. 4. ed. Petrópolis: Vozes, 1989. 
BORILLE, D. C. et al. A aplicação do método do arco da problematização na coleta de dados em pesquisa de enfermagem: Relato de experiência. Texto Contexto Enferm, v. 21, n. 1, p. 209-16, 2012.

BRASIL. Lei n. 5.692, de 11 de agosto de 1971. Estabelece as diretrizes e bases para o ensino de $1^{o}$ e $2^{o}$ graus. Brasília, 1971.

. Lei n.9.394, de 20 de dezembro de 1996. Estabelece as diretrizes e bases da educação nacional. Brasília. 1996.

. Ministério da Educação. Secretaria de Educação Fundamental. Parâmetros Curriculares Nacionais: apresentação dos temas transversais, ética. Brasília: MEC; SEF, 1997.

COPETTI, J. et al. Prevenção de doenças e agravos não transmissíveis como tema gerador para abordagem da saúde na escola. In: COPETTI, J.; FOLMER, V. (Org.). Educação e saúde no contexto escolar. Uruguaiana: Universidade Federal do Pampa, 2015. (Livro eletrônico).

COSTA, F. S.; SILVA, J. L. L.; DINIZ, M. I. G. A importância da interface educação/ saúde no ambiente escolar como prática de promoção da saúde. Informe-se em Promoção da Saúde, v. 4, n. 2, p. 30-33, 2008.

CYRINO, E. Trabalhando com estratégias de ensino-aprendizado por descoberta na área da saúde: a problematização e a aprendizagem baseada em problemas. Cad. Saúde Pública, v. 20, n. 3, p. 780-788, 2004.

DARIDO, S. C. Educação Física na escola: conteúdos, suas dimensões e significados. In: UNIVERSIDADE ESTADUAL PAULISTA. Prograd. Caderno de formação: formação de professores didática geral. São Paulo: Cultura Acadêmica, 2012. p. 51-75. V. 16.

DEUS, J. M. et al. Aula centrada no aluno versus aula centrada no professor. Desafios para mudança. Revista Brasileira de Educação Médica, v. 38, n. 4, p. 419-426, 2014.

FERNANDES, J. D. et al. Estratégias para a implantação de uma nova proposta pedagógica na escola de enfermagem da Universidade Federal da Bahia. Rev. Bras. Enferm., v. 56, n. 4, p. 392-395, 2003.

FRANÇA, F. C. V. A metodologia da problematização e a práxis docente na formação do enfermeiro. 2013. 160 f. Dissertação (Mestrado em Educação) - Universidade Católica de Brasília, Brasília, 2013.

FREIRE, P. Pedagogia da autonomia: saberes necessários à prática educativa. São Paulo: Paz e Terra, 1996.

GOMES, M. P. C. et al. O uso de metodologias ativas no ensino de graduação nas ciências sociais e da saúde - avaliação dos estudantes. Ciência \& Educação, v. 16, n. 1, p. 181-198, 2010. 
GUEDES, D.; GRONDIN, L. Percepção de hábitos saudáveis por adolescentes: associação com indicadores alimentares, prática de atividade física e controle corporal. Rev. Bras. Cienc. Esporte, v. 24, n. 1, p. 23-45, 2002.

MAIA, E. R. et al. Validação de metodologias ativas de ensino-aprendizagem na promoção da saúde alimentar infantil. Rev. Nutr., v. 1, p. 79-88, 2012.

MALTA, D. C.; MORAIS NETO, O. L.; SILVA JUNIOR, J. B. Apresentação do plano de ações estratégicas para o enfrentamento das doenças crônicas não transmissíveis no Brasil, 2011 a 2022. Epidemiol. Serv. Saúde, Brasília, v. 20, n. 4, p. 425-438, 2011.

MARIN, M. J. S. et al. Aspectos das fortalezas e fragilidades no uso das metodologias ativas de aprendizagem. Revista Brasileira de Educação Médica, v. 34, n. 1, p. 13-20, 2010.

MARINHO, J. C. B.; SILVA, J. A.; FERREIRA, M. A educação em saúde como proposta transversal: analisando os Parâmetros Curriculares Nacionais e algumas concepções docentes. História, Ciências, Saúde, Manguinhos, v. 22, n. 2, p. 429-443, 2012.

MELO, E.; LUFT, V.; MEYER, F. Obesidade infantil: como podemos ser eficazes? Jornal de Pediatria, v. 80, n. 3, p. 173-182, 2004.

MELO, M. C. A residência como cenário educativo para enfermeiros: o uso da metodologia da problematização. 2013. 119 f. Dissertação (Mestrado Profissional em Ensino na Saúde) - Escola de Enfermagem Aurora de Afonso Costa, Niterói, 2013.

MENDES, E. Análise da metodologia de ensino de sequências didáticas. Revista Eletrônica de Educação e Ciência (REEC), v. 5, n. 1, p. 71-80, 2015.

MOREIRA, M. A. Aprendizagem significativa: um conceito subjacente. Aprendizagem Significativa em Revista, v. 1, n. 3, p. 25-46, 2011.

ORGANIZAÇÃO MUNDIAL DA SAÚDE. Global Status Report on Noncommunicable Diseases. 2014. Disponível em: <http://apps.who.int/iris/bitstream/10665/148114/1/9789241564854_eng.pdf?ua=1>. Acesso em: 21 dez. 2016.

PEDROSA, I. L. et al. Uso de metodologias ativas na formação técnica do agente comunitário de saúde. Trab. Educ. Saúde, v. 9, n. 2, p. 319-332, 2011.

RONCA, A. C. C. Teorias de ensino: a contribuição de David Ausubel. Temas psicol. [on-line], v. 2, n. 3, p. 91-95, 1994.

SANTOS, A. L.; CARVALHO, A. L.; GARCIA JUNIOR, J. R. Obesidade infantil e uma proposta de Educação Física preventiva. Motriz, v. 13, n. 3, p. 203-213, 2007. 